\title{
Eduardo Palmério, um perfil intelectual: humorismo e cultura política nas crônicas da imprensa paulista dos anos 1940
}

\author{
André Azevedo da Fonseca*
}

\begin{abstract}
Resumo
Eduardo Palmério (1906-1076) foi um cronista muito popular que atuou na imprensa paulistana entre as décadas de 1940 e 1970. Suas crônicas eram marcadas por um grande senso de humor, pela crítica social e pela postura política independente. Nesse artigo, por meio de um perfil intelectual fundamentado em análise de documentação primária e secundária, procuramos recuperar a memória deste cronista, relacionando os temas de sua produção às ideias políticas em voga no período de abertura democrática na segunda metade dos anos 1940. Constatamos que as crônicas de Palmério reverberavam uma cultura política presente na opinião pública, que deixava de lado os sectarismos ideológicos e partidários do período para conceber o desenvolvimento da sociedade brasileira pela perspectiva da moral e da ética humanista.

Palavras chave: Crônica brasileira. Imprensa paulista. História da imprensa. Humorismo. Mídia e sociedade.
\end{abstract}

Eduardo Palmerio, an intellectual profile: humorism and political culture in the chronicles of the São Paulo press during the 1940's Abstract

Eduardo Palmerio (1906-1076) was a popular columnist who worked in the Sao Paulo press in the decades of 1940's to 1970's. His chronicles were characterized by a great sense of humor, social criticism and independent political stance. In this article we try to recover the memory of the chronicler through an intellectual profile followed by a documental analysis, relating the themes of his works

* Professor adjunto no Departamento de Comunicação, Centro de Educação Comunicação e Artes da Universidade Estadual de Londrina (CECA/UEL), Londrina-PR, Brasil. Doutor em História (Unesp) com pós-doutorado em Estudos Culturais no Programa Avançado de Cultura Contemporânea (PACC/UFRJ). Integrante do grupo de pesquisa "Comunicação e História" da Universidade Estadual de Londrina (UEL). E-mail: azevedodafonseca@gmail.com

Intercom - RBCC

São Paulo, v.35, n.2, p. 6I-84, jul./dez. 2012

61 
to the political ideas in vogue during the period of democratic opening of the second half of the 1940's. We found that the chronicles of Palmerio reverberated a political culture present in the public opinion that went beyond the ideological sectarianism and parties of that period to conceive the development of Brazilian society from the perspective of moral and humanistic ethics.

Keywords: Brazilian Chronicle. São Paulo Press. History of brazilian press. Humor. Media and society

\section{Eduardo Palmério, un perfil intelectual: humorismo y cultura política en las crónicas de la prensa paulista de los años 1940 Resumem}

Eduardo Palmério (1906-1076) fue un cronista muy popular que actuó en la prensa paulistana entre las décadas de 1940 y 1970. Sus crónicas eran marcadas por un gran sentido del humor, por la crítica social y por la postura política independiente. En este artículo procuramos recuperar la memoria de este cronista por medio de un perfil intelectual seguido del análisis documental, relacionando los temas de su producción a las ideas políticas en boga en el período de apertura democrática en la segunda mitad de los años 1940. Constatamos que las crónicas de Palmério reverberaban una cultura política presente en la opinión pública, que dejaba de lado los sectarismos ideológicos y partidarios del período para concebir el desarrollo de la sociedad brasileña por la perspectiva de la moral y de la ética humanista.

Palabras clave: Crónica brasileña. medios de comunicación en São Paulo. Historia de la prensa, Humor. Medios y la sociedad.

\section{Introdução}

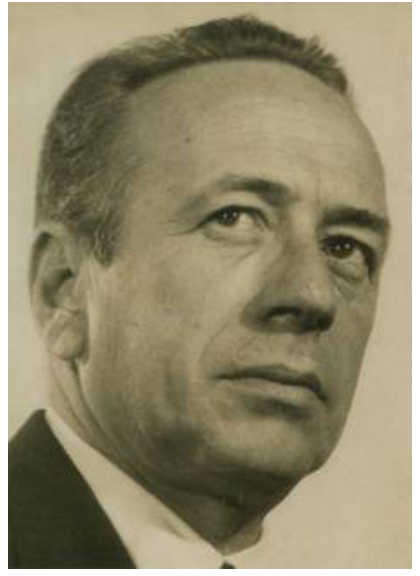

Retrato de Eduardo Palmério, década de 1950
Tuardo Palmério (1906-1976), irmão mais velho do célebre escritor Mário Palmério, foi um cronista talentoso que conquistou popularidade na imprensa paulistana a partir de meados dos 1940 até o início dos anos 1970. Talvez pelo fato de ter sido um jornalista interiorano que, apesar de morar em São Paulo, manteve-se distante dos badalados "grupos de sociabilidades" intelectuais da capital (GAMA, 1998), Eduardo nunca é mencionado, sequer nas notas de rodapé, quando se registram a história ou as 
memórias da crônica contemporânea brasileira (FUNDAÇÃO CASA DE RUI BARBOSA, 1992); do Jornalismo de humor no Brasil (RUI, 1979), (PIMENTEL, 2001) ou, naturalmente, da história da imprensa paulista ou brasileira, tal como nos estudos de Nobre (1950), Duarte (1970), Sodré (1998), Martins; De Luca (2008) e Barbosa (2007).

Essa omissão, como procuraremos demonstrar, não faz jus à qualidade dos textos e à sensibilidade do cronista, que refletiu com bom humor, criatividade, independência política e vigor intelectual as principais questões de seu tempo. Graças à popularidade do Diário da Noite, que tinha enorme vendagem em São Paulo (MATTOS, 2002, p.65), Palmério alcançava um número considerável de leitores, de modo que popularizou sua visão de mundo e influenciou a opinião pública, interpretando com muito senso de humor o espírito e as contradições de sua época, zombando de temas os mais diversos, das polêmicas da cantora Maysa (LIRA NETO, 2007, p.112) às profissões em ascensão importadas dos Estados Unidos, como a de Relações Públicas (ANDRADE, s/d). Palmério publicou quatro livros. Duas de suas obras são listadas na Enciclopédia de literatura brasileira (COUTINHO; SOUZA, 2001, p. 474; p. 797). Contudo, seus livros estão fora de catálogo há mais de 50 anos. Além disso, não há estudos acadêmicos sobre a sua obra.

Por meio de um perfil intelectual, fundamentado em análise documental, este artigo tem o objetivo de recuperar um autor relevante na história da crônica brasileira, discutir a sua produção intelectual e identificar os temas que inspiraram as suas principais crônicas. Com isso, o estudo procura contribuir com a análise da cultura política e dos princípios éticos e morais que encontravam ressonância em parte significativa da opinião pública paulista na segunda metade dos anos 1940, período efervescente da chamada "experiência democrática" brasileira. Quais ideias políticas sustentavam a prosa de Eduardo Palmério? Em que medida esse humorista e crítico social dialogava com a cultura política de seu tempo? Enfim, qual a importância das crônicas de Eduardo Palmério para a compreensão do debate político brasileiro após o fim da ditadura Vargas? 
Como se trata de um perfil intelectual, optamos por estabelecer um recorte inspirando-nos na concepção de Vilas Boas (2003, p.13), para quem o perfil tem a liberdade de focalizar "apenas alguns momentos da vida da pessoa" em vez de abordar, necessariamente, toda a cronologia do personagem estudado. O período analisado compreende a fase mais produtiva de Eduardo Palmério em termos editoriais, situada no final dos anos 1940. Para a fundamentação teórica empregamos o conceito de Philippe Levillain, para quem a biografia historiográfica torna-se particularmente importante quando assume uma função:

(...) a meio caminho entre o particular e o coletivo, exercício apropriado para identificar uma figura num meio, examinar o sentido adquirido por uma educação distribuída a outros segundo os mesmos modelos, analisar as relações entre o desígnio pessoal e forças convergentes ou concorrentes, fazer o balanço entre o herdado e o adquirido em todos os domínios (LEVILLAIN, 2003, p.165).

A pesquisa emprega o método da análise documental, utilizando fontes primárias e secundárias. Como registra Moreira (2005), essa metodologia consiste em "um conjunto de operações intelectuais que têm como objetivo descrever e representar os documentos de maneira unificada e sistemática para facilitar a sua recuperação". Contudo, mais do que apenas "localizar, identificar, organizar e avaliar textos", essa análise se configura como um procedimento eficaz para estabelecer a contextualização dos dados em um conjunto coerente e original. "Consegue dessa maneira introduzir novas perspectivas em outros ambientes, sem deixar de respeitar a substância original dos documentos. (MOREIRA, 2005, p.276). A pesquisa está situada no campo da história cultural e da história da imprensa.

\section{Origens}

Eduardo Palmério nasceu na cidade de Sacramento (MG), na região do Triângulo Mineiro, em 1906. Seu pai, o italiano Francisco Palmério, era engenheiro, jornalista, advogado e agrimensor, tendo conquistado bastante prestígio na região. No final da década de 
1910, a família se transferiu para a cidade de Uberaba (MG), onde Eduardo concluiria os estudos. Na juventude, ele cursou a faculdade de Odontologia na Universidade do Brasil, no Rio de Janeiro, e ficou deslumbrado com a vida cultural carioca e com a vitalidade da imprensa da capital (FONSECA, 2006). De volta a Uberaba Eduardo começou a exercer a odontologia, mas o entusiasmo pelos livros levou o jovem dentista a fundar, em 1931, a Livraria ABC, que nos anos seguintes se tornaria um confortável ponto de encontro das elites ilustradas uberabenses (LIVRARIA ABC, 1956).

No início do século 20, Uberaba era uma localidade cuja economia dependia basicamente da criação de gado Zebu. A cidade já havia passado por um período de dinamismo comercial no século 19, quando foi considerada o centro político e econômico da região. "Contudo, diversos fatores a levaram à derrocada econômica, de modo que o processo de modernização foi interrompido, a área urbana sofreu um sensível processo de decadência e a cidade acabou por perder parte de sua influência regional." (FONSECA, 2010, p.16).

Contudo, a partir dos anos 1930, a cidade experimentou um período de renascimento urbano, o que estimulou as atividades do comércio e o consequente surgimento de novos periódicos na imprensa local. Nesse período, o jovem Palmério já escrevia esporadicamente nos jornais locais. Em 1931, ele chegou a fundar dois periódicos: O Turf e Política (MENDONÇA, 1948, p.2) - iniciativas que não duraram muito tempo - e, no primeiro semestre de 1933, dirigiu a Gazeta de Uberaba (TOTI, 1949, p.72) - periódico tradicional na cidade. No diário local Lavoura e Comércio - o mais importante da região - por meio da coluna Zebulândia, este rapaz já conhecido pela boa conversa e pelos ditos espirituosos pôde exercitar seu talento em descrever os "pequenos ridículos das coisas" - nas palavras do colega jornalista Santino Gomes de Matos (1948, p.1).

A propósito, entre os sete irmãos, Eduardo Palmério era aquele que se movimentava com mais desenvoltura nos circuitos das elites de Uberaba. Naqueles primeiros anos da década de 1940 ele já era um ator consciente do bom desempenho de seu papel social. Para circular nos grupos de status ligados às elites intelectuais, Eduardo 
atuava como orador em reuniões do Rotary Clube, lisonjeando com muita habilidade as figuras eminentes que participavam do círculo. A nota de seu próprio aniversário na coluna social do Lavoura e Comércio é um bom indicador de seu prestígio:

Marca o dia de hoje a data natalícia do sr. dr. Eduardo Palmério, conceituado sócio da firma proprietária da "Livraria A.B.C." e pessoa muito estimada e relacionada em nossos meios sociais, onde conta com um dilatado círculo de amigos e admiradores de suas qualidades de coração caráter (sic), e de sua formosa inteligência de humorista dos mais apreciados.

Pelos seus dotes personalíssimos o distinto aniversariante desfruta de geral estima e consideração em nossa cidade devendo, por isso mesmo, receber hoje as mais expressivas homenagens, às quais nos associamos (DR. EDUARDO, 1941, p.2).

Mais tarde, a Livraria $\mathrm{ABC}$ parece não ter se tornado um empreendimento promissor, pois em junho de 1941 - ou seja, após dez anos de teimosa insistência - acabou fechando as portas. "Nada mais ilusório do que o aspecto imponente de algumas de nossas livrarias: não passam de meras salas de estar para o conforto de intelectuais vadios e prontos, estes eternos bolinadores de livros, que jamais fizeram soar o tímpano das caixas registradoras." (PALMÉRIO, 1949, p.54). De fato, quando ele anunciou na imprensa o encerramento das atividades comerciais, pediu expressamente que os fregueses em débito o procurassem para acertar as contas. (A LIVRARIA, 1941, p.6).

Em 1943, chegou a escrever algumas crônicas na coluna "Balões de ensaio", do Lavoura e Comércio. Mas como não era possível ganhar a vida como jornalista naquela cidade provinciana, Eduardo Palmério decidiu realizar um novo curso de atualização em Odontologia em São Paulo e reabrir o consultório. (DR. EDUARDO, 1943, p.3). A imprensa local noticiaria esse fato com grande entusiasmo: em cinco parágrafos de texto, Palmério foi descrito como "um dos mais abalizados profissionais que já tem exercido essa delicada profissão nesta cidade”. (FONSECA, 2010).

Contudo, desiludido com a perspectiva de ser obrigado a admitir como última opção a carreira de dentista naquela pequena 
e presunçosa cidade, em 1943, Eduardo Palmério deixou Uberaba definitivamente para ganhar a vida como jornalista em São Paulo (MEDICI, 2006, p.2).

$\mathrm{Na}$ imprensa paulistana ele rapidamente se tornou um comentarista empenhado em criticar os costumes de grã-finos, empresários e políticos. Essa habilidade certamente havia sido exercitada na observação direta dos círculos de elite de sua pequena Uberaba. Talvez mais por diversão do que por algum receio em assinar seus textos, Palmério passou a adotar vários pseudônimos. O mais famoso deles era "Camarada Lorotoff" - provavelmente uma dupla zombaria com a paranóia anticomunista e ao mesmo tempo com a "lorota" comunista. Com essa assinatura ele publicou, em 1948, o livro-reportagem A Grande Mamata - uma série de reportagens realizadas para os Diários Associados, relatando as fraudes na indústria do leite no interior paulista.

E é a partir daqui que pretendemos observar a originalidade de seu estilo de reportagem com um texto repleto de trocadilhos e ditos espirituosos. Palmério afirmava que, nas atividades de produção de leite, só havia um inocente: "a vaca". Segundo ele, todos os homens que participavam dessa indústria eram criminosos. Para chegar nessas conclusões, o jornalista fez uma excursão - ou, como brincava, uma verdadeira "via láctica" - pelo Vale do Paraíba (SP), visitando fazendas e centros de produção de leite; verificando as condições sanitárias dos vasilhames; conversando com vaqueiros; acompanhando o processamento do leite, da produção ao transporte, até aos estabelecimentos de venda; e analisando também os documentos do Serviço de Policiamento de Alimentação Pública. Sua conclusão foi que todo o leite que se bebia em São Paulo estava "avacalhado" e era "absolutamente impróprio para menores". Sessenta por cento das amostras, garantia o jornalista, continham água. Até cloro foi encontrado no leite entregue à população. Além disso, registrou, era indescritível a sujeira verificada no principal alimento dos meninos. "Matar o leite, despojá-lo de todos os seus elementos nutritivos, não é laticínio, é latrocínio. Mas que é negócio, é." Por tudo isso, a indústria de leite era chamada de "grande mamata", um ofício que engordava apenas "os fraudadores, os inescrupulosos, os usineiros sem consciência, 
os monopolizadores, os tubarões, os que não temem enriquecer à custa da infelicidade alheia”. (MENDONÇA, 1948, p.2).

Naturalmente, a verve de cronista seria exercitada, sobretudo, no cotidiano da imprensa paulistana, quando assumiu a coluna "Ponto e Vírgula" no Diário da Noite - jornal muito popular na década de 1940 (Barbosa, 2007, p.109). Em 1949, Eduardo Palmério organizou as melhores crônicas dos últimos anos e as republicou no livro 100 Comentários Separados do B.O.D.E.: Boletim Oficial do Estado, lançado pela prestigiosa editora José Olympio. Em 1951, lançaria ainda Solteiros no civil e no religioso, seu primeiro romance, encenado no ambiente característico dos jornais paulistanos. Alguns anos depois, ele lançaria ainda a ficção A noite é nossa (1958) e continuou escrevendo na imprensa paulistana até as vésperas de sua morte, no dia 4 de janeiro de 1976, aos 69 anos de idade.

\section{Um novo cronista em São Paulo}

Tendo em vista os objetivos do presente estudo, é interessante estabelecer uma análise do livro 100 Comentários: Separados do B.O.D.E. Boletim Oficial do Estado; lançado em 1949. Nesta obra, Eduardo Palmério selecionou o que considerava mais representativo em sua produção jornalística nos anos anteriores e, exatamente por isso, a antologia parece bastante significativa para identificarmos elementos fundamentais de suas ideias políticas e de seu universo de referências.

Se o cronista é um intérprete de seu tempo, o estudo sobre Eduardo Palmério contribui para interpretarmos os temas e conceitos que movimentavam a opinião pública daquele período. Cândido (FUNDAÇÃO CASA DE RUI BARBOSA, 1992, p.22), argumenta que uma das principais qualidades da crônica está justamente na "sua capacidade de traçar o perfil do mundo e dos homens". Nas palavras de Arrigucci Jr. (2001, p.63) o cronista, atuando na imprensa, é uma espécie de narrador dos fatos do cotidiano da cidade moderna. A crônica, portanto, seria "o registro dos instantâneos da vida moderna, das novidades avassaladoras, dos rápidos acontecimentos, dos encontros casuais, dos estímulos sempre chocantes do cotidiano das grandes cidades, frutos da aceleração 
do processo de urbanização e industrialização da década de 30 ". Coutinho (1978), por sua vez, procura firmar as diferenças entre os diversos gêneros da produção jornalística, notando que, se as notícias procuram a objetividade e a imparcialidade, a crônica deve ser caracterizada pela sua ligação pessoal, lírica e subjetiva com os fatos cotidianos que a inspiram. Assim, comunica-se intensamente com o imaginário dos leitores, inspirando interpretações criativas dos fatos noticiados pelos jornais, ou expressando as opiniões não manifestas dos leitores.

Destacamos que na escrita do cronista se encontram elementos do imaginário de seu tempo, nas crônicas de Eduardo Palmério, os políticos eram sempre ignorantes, abobalhados e coçavam a cabeça para pensar. "Mas o ministro não dorme de botina. Raciocina com pouca profundidade, mas com muita rapidez (PALMÉRIO, 1949, p.8)" - escreveu certa vez. Em geral, todas as corporações do Estado eram desmoralizadas, tal como notamos neste trecho: "O Laboratório da Polícia Técnica de São Paulo fez uma descoberta mais importante que a da pólvora sem fumaça ou a da fumaça sem pólvora: descobriram que o 'pif-paf' é jogo de azar!" (PALMÉRIO, 1949, p.49). Quando comentou sobre um expressivo aumento nas taxas de reembolso postal no país, encarecendo, por exemplo, a compra de livros pelos Correios, Palmério lançou argumentos indignados: "Governar um país de analfabetos é a suprema delícia de políticos semianalfabetos. E por isso fazem guerra ao livro, perseguem os autores, os editores e até mesmo os leitores." (PALMÉRIO, 1949, p.56). Em outro texto, ao defender o sindicato dos barbeiros, que na ocasião exigia um acréscimo de 80\% nos salários da categoria, o jornalista argumentou: "considerando-se que a função do barbeiro é muito mais útil à comunidade do que a dos deputados, só nos resta apoiá-los - os barbeiros, não os deputados." (PALMÉRIO, 1949, p.123). Essa ofensiva é um sinal eloquente da emergente sociedade civil que agitava a opinião pública na segunda metade dos anos 1940, quando, após a queda de Vargas, os cidadãos começaram a perder o receio de exercitar as prerrogativas da liberdade de expressão. Como mostram Martins e De Luca (2006), a extinção do Departamento Nacional de Informação (DIP), criado na ditadura Vargas, e o desaparecimento 
em setembro de 1946 do Departamento Nacional de Informação (DNI), uma espécie de sucessor do DIP, sinalizaram claramente o afrouxamento do controle da imprensa no país. Para um jovem jornalista interiorano que vivera sob a ditadura, a oportunidade de atacar o governo e zombar da classe política naquele período convencionalmente chamado de "experiência democrática" era um deleite impagável.

O combate a favor da leitura seria um tema sempre presente nas crônicas que viria a escrever na imprensa. Em um artigo publicado na década de 1940, Palmério defenderia com entusiasmo a ideia de que os livros custavam relativamente pouco naquela época. "Pode-se morrer de fome no Brasil por falta de dinheiro para comprar comidas, mas ninguém morre de burrice por falta de dinheiro para comprar livros." Para demonstrar sua tese, o irônico cronista teve o cuidado de comparar preços de produtos de modo inusitado: "Um romance de Eça de Queiroz vale bem mais do que um quilo de bacalhau, e custa bem menos". Palmério lembrou também que era possível encontrar, nos sebos paulistas, livros de Jorge Amado pelo custo de "dois palmos de linguiça" e cartilhas escolares pelo preço de um maço de cigarros. Para ele, o problema era que as pessoas, em geral, não davam valor aos livros. O próprio governador mineiro, Benedito Valadares, era desses que não entrava em livraria "nem para se esconder da chuva" - zombava o cronista, concluindo que: "Ninguém é burro por falta de dinheiro, - a maioria o é por excesso..." (PALMÉRIO, 1949, p.169).

A zombaria ao Estado e ao poder, um dos signos da abertura política do período, tornou-se um elemento permanente na produção intelectual de Eduardo Palmério. E dentre os temas muito discutidos da época destacava-se a historicamente problemática questão eleitoral - um mote que se tornaria central na obra do irmão, Mário Palmério (1956). Na Primeira República, sabemos que as fraudes eram generalizadas e ocorriam em todas as fases do processo de votação (NICOLAU, 2004, p.34). Durante o Estado Novo (1937-1945) as eleições foram suspensas; porém, com o retorno do processo democrático, em 1945, e, sobretudo, com a Constituição de 1946, o número de eleitores aumentou sensivelmente, suscitando uma série de discussões sobre a democracia 
de massa no país (PALMÉRIO, 1949, p.46). Assim, em um artigo sobre a necessidade da construção de novos cemitérios, o escritor observou que, antigamente, os mortos eram melhor tratados pelo Estado: "É que nos velhos tempos (...) os defuntos votavam, decidiam seriamente a sorte dos pleitos políticos, e por essa razão mereciam atenção dos poderes públicos." (PALMÉRIO, 1949, p.36). Em outro momento, ao lamentar a instalação de máquinas para agilizar o processo eleitoral no Brasil, ele escreveu: "Há dezenas de anos que os brasileiros votam maquinalmente, mesmo sem máquinas, e nem por isso as coisas vão indo melhor." (PALMÉRIO, 1949, p.11).

Mas ainda que se mostrasse crítico contra as forças políticas conservadoras, Palmério mantinha uma postura bastante cética em relação a algumas das bandeiras sociais mais caras da época. Quando os músicos profissionais discutiam a sindicalização da classe, por exemplo, o jornalista simplesmente desdenhou: "Pobre gente que ainda acredita em sindicatos, em união de classe e quejandas mais! Não adianta, não adianta! Em matéria de arte, quem não vencer sozinho, sindicalizado pior ainda. Um sindicato é a coisa menos harmoniosa do mundo, e a música, sem harmonia, sabem o que é..." (PALMÉRIO, 1949, p.24). Apenas a Associação dos Palhaços obteve seu espirituoso apoio, quando essa entidade realizou um protesto contra o costume disseminado dos membros da Câmara Municipal de São Paulo de se chamarem mutuamente de palhaços - ofendendo, inversamente, toda uma classe de trabalhadores circenses que não queriam ser associados à má reputação dos vereadores (PALMÉRIO, 1949, p.57).

Não é fácil identificar as preferências partidárias de Eduardo Palmério - talvez porque seu espírito independente não se sujeitasse às opções em voga na época, ou porventura devido à notória falta de clareza expressa nos programas dos partidos políticos; ou mesmo por influência da tradição editorial do Diário da Noite, que, como notou Sodré (1998, p.366), pelo menos no final dos anos 1920 não tinha o compromisso editorial de apoiar o governo, e tampouco estabelecia vínculos com a organização partidária - ao contrário, por exemplo, do jornal udenista Tribuna da Imprensa, criado em dezembro de 1949 no contexto da organização das forças

Intercom - RBCC

São Paulo, v.35, n.2, p. 6I-84, jul./dez. 2012

71 
anti-getulistas, e o francamente varguista Última Hora (MARTINS; DE LUCA, 2006, p.81). Na época, os constitucionalistas liberais que se opunham a Getúlio Vargas militavam através da União Democrática Nacional (UDN); os antigos queremistas que defendiam o projeto de Vargas acabaram se institucionalizando no Partido Trabalhista Brasileiro (PTB); por fim, o Partido Social Democrático (PSD) reuniu os tradicionais chefes políticos do interior que, por sua vez, também apoiavam Vargas. Entretanto, nenhuma das três legendas - e menos ainda o Partido Comunista - pareciam representar os ideais de Eduardo Palmério - e não é um despropósito supor que, em termos programáticos, tampouco representavam a opinião da massa da sociedade brasileira.

Ao criticar um aumento de subsídios que os deputados haviam concedido a si mesmo, por exemplo, o cronista defendeu que os culpados pelo projeto "imoral", "antipatriótico" e "ignóbil" eram o PSD, "por ter apoiado publicamente a iniciativa", e a UDN, "por tê-la aparentemente combatido, mas não ter tomado nenhuma medida prática para evitar a consumação do odioso atentado ao decoro do Parlamento" (PALMÉRIO, 1949, p.106). No entanto, Eduardo tampouco se mostrava petebista ou getulista. Ao contrário, em um artigo lamentando a carência de bons oradores políticos capazes de "inflamar as massas, orientá-las, levá-las em fulminantes arrancadas ao término das grandes cruzadas cívicas", o jornalista dedicou todo um parágrafo para criticar o ex-ditador:

Getúlio acabou com tudo isto. Criou o verbo enlatado, a palavra condicionada; censurou o entusiasmo, codificou o qualificativo e desqualificou a sinceridade. Substituiu tudo o que tinha de nobre e de criador na palavra livre e quente dos improvisos, pela palavra oficial, dipificada e mistificada, insincera e servil. Getúlio consagrou o elogio dirigido, apossou-se de todas as tribunas, que só eram permitidas, quando se transformassem numa catadupa de laudatórios à sua excelentíssima pessoa ou ao seu excelentíssimo governo.Getúlio destruiu o verbo, enquanto os seus amigos, calmamente, iam destruindo as verbas... (PALMÉRIO, 1949, p. 182)

Em um artigo comentando as greves que agitavam aquele período, o autor ponderou que, frequentemente, tanto os empregados quanto os empregadores tinham razão. "O que não é justo 
é querer acabar com as greves a muque, 'manu militari', sem ouvir com atenção e pesar com equidade os argumentos contrários." Para ele, era verdade que muitos patrões cometiam injustiças; no entanto, era igualmente notório que havia, no meio proletário, inúmeros "agitadores profissionais que só se interessam pela desorganização do sistema econômico do país”. (PALMÉRIO, 1949, p.191-192). Isso relativiza a ideia de que o período foi marcado por uma inevitável polarização política. Sua independência sugere uma análise que contemple a complexidade das posições políticas dos eleitores daquele tempo.

Sem identificar quaisquer vínculos partidários diretos, podemos constatar que a perspectiva igualitária do discurso de Eduardo Palmério era eminentemente moral e humanista - o que oferece alguns indícios para interpretar elementos da cultura política brasileira da época. "Todos nós, devemos acentuar preliminarmente, ao nascermos, somos iguais. Este é um princípio cristão, profundamente humano, divino mesmo." (PALMÉRIO, 1949, p.77). Até mesmo em seus textos mais satíricos podemos notar a crítica social e o esforço para se pensar uma nova ordem para a sociedade brasileira fundamentada mais em termos éticos e morais do que ideológicos e partidários. Essa disposição ficou registrada pelo próprio autor, no prefácio que ele mesmo escreveu para o romance A noite é nossa:

Afirmam os homens 'sensatos' que é perigoso mudar a ordem natural das coisas. Mas pergunto: essa ordem é natural? Acredito que, no desejo de melhorar nossas condições particulares ou gerais, toda insensatez é perfeitamente justificada. Mais vale errar por conta própria do que deixar que acertem por nós (PALMÉRIO, [1958], p.9).

\section{A crítica aos valores burgueses}

Ainda que a zombaria político-partidária seja um elemento muito presente em suas crônicas, o traço que talvez mais caracterize a crônica de Eduardo Palmério é a sua crítica geral ao universo de valores da burguesia.

Em 1940, aos 34 anos, Palmério se movimentava com bastante desenvoltura pela sociedade uberabense e empreendia es-

Intercom - RBCC

São Paulo, v.35, n.2, p. 6I-84, jul./dez. 2012 
forços conscientes para participar daqueles circuitos. É evidente que, quando ainda estava em busca de estima social o cronista silenciava suas críticas para participar das trocas de louvores que animavam a sociabilidade naquela cidade interiorana.

Assim, Eduardo Palmério sempre foi entusiasticamente louvado pelos pares na imprensa de Uberaba. Por ocasião do lançamento de A grande mamata (1948), Ruy Novais louvou sua "vigorosa personalidade literária" e a sua "agilidade mental" (NOVAIS, 1948, p.2), Santino Gomes de Matos celebrou sua "verve rica e copiosa" e sua "veia incomparável de humorista" (MATOS, 1948, p.1), e José Mendonça afirmou que o autor pertencia "à estirpe gloriosa dos satíricos, dos que sabem, com jocosidade, mas, também, com energia e indignação, fustigar os vícios e açoitar os inimigos do povo". (MENDONÇA, 1948, p.2). Em 1949, quando Eduardo lançou 100 comentários, Ruy Novais estamparia no título: "É uberabense um dos maiores humoristas do Brasil". (NOVAIS, 1949, p.3). Em 1951, por ocasião da publicação de Solteiros no civil e no religioso, José Mendonça escreveu: "Está de parabéns a literatura nacional" (MENDONÇA, 1951, p.2); Ruy Novais enalteceu o que considerava o maior êxito literário de sua carreira já vitoriosa (NOVAIS, 1951, p.6); e João de Minas registrou: "Para mim, Eduardo Palmério, que tem também muitos defeitos, é um puro gênio. É um talento formidável! E meu mestre, ainda tenho a honra de dizer." (MINAS, 1952, p.2). Em 1958, na publicação de A noite é nossa, José Mendonça declarou que este era "mais um livro digno da nossa admiração e dos nossos mais vivos aplausos" (MENDONÇA, 1958, p.2). Os exemplos são muitos, mas servem para mostrar, acima de tudo, as boas relações travadas por Palmério em sua terra.

Ainda assim, naquele desiludido ano de 1943, quando estava prestes a se mudar para São Paulo, o jornalista começou a expressar a sua aversão àquele mesmo conjunto de valores que antes aplaudia. Em uma de suas últimas crônicas que publicou no Lavoura e Comércio antes de partir da cidade, por exemplo, Palmério já esboçava uma crítica à hipocrisia de sociedades que se baseavam na opinião alheia e nas redes de convenções (PALMÉRIO, 1943a, p.4). Em outra ocasião, contando um caso que supostamente presenciara em um café no centro da cidade, Pal- 
mério ridiculariza um grupo de homens que se acercavam de um cidadão "elegantemente enfarpelado", com ares de sujeito muito importante na vida. Após constatar que o indivíduo era realmente alguém de muito renome, mas que ele próprio, Eduardo Palmério, desconhecia, eis que ele passa a narrar, com deliciosos pormenores, a cômica e dissimulada subserviência dos bajuladores.

Nisto um dos camaradas do grupo correu ligeiro a pagar-lhe o café, enquanto os outros providenciaram-lhe imediatamente um lugar no balcão.

Uma chuva de cumprimentos caiu-lhe sobre a personalidade marcante. Todos se interessavam pela sua saúde, pelos seus negócios, pelas suas conquistas e pelo seu belo automóvel. (...)

Um pôs-lhe o açúcar na chícara (sic), outro recomendou à menina que não lhe pingasse café no belo azul do terno; outro, ainda, tirou-lhe uma linha que inadvertidamente balouçava na fímbria de seu caríssimo chapéu.... (PALMÉRIO, 1943b, p.6).

Quando Palmério perguntou quem era, afinal, aquele ilustre sujeito, notou que as pessoas chegaram a se apiedar dele, pelo fato de não conhecer um cidadão de tão alta projeção social. Tratava-se de "Fulano de tal", homem envolvido em um negócio obscuro envolvendo 500 contos, que fora inclusive processado, mas que conseguira "abafar tudo" e embolsar a fortuna. "Mas é um belo camarada, (...) não faz nenhum alarde disso", disseram os bajuladores, para o desgosto do cronista.

Em São Paulo, Palmério sentiu-se ainda mais livre para criticar os comportamentos e instituições burguesas. Em uma crônica sobre novos aparatos da medicina plástica, o jornalista simulou um diálogo de uma distinta senhora em busca de distinção nos seguintes termos:

Sobrancelhas de rayon, aconselhadas às senhoras da alta classe, pelo ar de alta distinção que conferem, são encontradas em qualquer loja de cinco centavos na quinta-avenida e imediações. Narizes aristocráticos, providos de depósitos aromáticos ao gosto do distinto cliente, aquilinos, elegantíssimos, em cores sortidas, compram-se sob medida, em qualquer instituto de beleza, para adultos e crianças de ambos os sexos (PALMÉRIO, 1949).

Além da encenação que as elites travavam pelos jornais burgueses, a tendência de a imprensa da época deformar os fatos seria um dos temas sempre presentes de sua prosa. 
O seu Manuel da esquina não lê jornais. Bem que assina um dos nossos maiores matutinos, por causa do tamanho que é grande, e do papel que é forte e dá excelentes embrulhos. É proibido por lei embrulhar mercadorias em papel de jornal, mas como o seu Manuel da esquina não os lê, ignora os dispositivos legais, e faz os seus embrulhos inocentemente; também, que diabo! Se os jornais vivem embrulhando o povo, porque não permitir que com eles se embrulhem carne, verduras, frutas e outras raridades? (PALMÉRIO, 1949).

Em outro artigo, ele conta o caso de um sujeito que havia sido dado como morto pelos jornais, mas que o procurara para esclarecer os leitores de que não havia falecido. Palmério não deixou de aproveitar o caso para ironizar, mais uma vez, o divórcio aparentemente irreconciliável entre a imprensa e a realidade.

(...) pelo simples fato do sr. Rosomar se declarar vivo, não iremos desmentir os nossos colegas de imprensa que, se noticiaram o falecimento, naturalmente possuem motivos que justifiquem esta publicação. (...) Se os jornais declaram que um cidadão está morto, não é admissível que este cidadão venha a público desmentir uma notícia afirmada por uma dezena de jornais perante alguns milhões de leitores! (PALMÉRIO, 1949, p. 103).

\section{Economia e sociedade}

Eduardo Palmério deixou algumas pistas para identificarmos suas ideias sobre a política econômica brasileira - sugerindo, mais uma vez, novos caminhos para reinterpretarmos a opinião pública da época. Naquele período, o presidente Dutra ainda buscava um rumo para a economia nacional. Em uma primeira fase compreendida entre 1946 e 1947, o governo ensaiou um retorno aos princípios do liberalismo ao abrir o país à importação; contudo, a experiência fracassou rapidamente devido ao esgotamento das reservas brasileiras e ao déficit no balanço de pagamentos. A partir de junho de 1947 uma nova política de controles cambiais e uma tendência para o planejamento dos gastos federais foram os principais elementos de um segundo período econômico que acabou marcado por um surto de industrialização espontânea. No final da década de 1940 foi estabelecido um grande debate sobre as estratégias que o Brasil deveria tomar em relação ao desenvolvimento. 
Uma comissão técnica mista, destinada à cooperação econômica entre Brasil e Estados Unidos, publicaria, em 1949, o Relatório Abbink, marcado por um teor fortemente neoliberal que pregava medidas financeiras e fiscais bastante ortodoxas. Mas um grupo de jovens economistas ligados à Confederação Nacional da Indústria, no Rio de Janeiro, contestaram o relatório, argumentando que o aumento real das rendas dos trabalhadores deveria ser o ponto central da política econômica, ainda que à custa de certa inflação (SKIDMORE, 1979, p.96-101).

As ideias políticas e econômicas de Eduardo Palmério trouxeram essas macro-discussões para o chão do senso comum e, por isso, oferecem filtros interessantes para verificarmos de que modo aquelas ideias repercutiam entre os estratos escolarizados da sociedade brasileira. Como evidencia Michel Winock (In: REMOND, 2007, p.271-294) as ideias políticas que movimentam o seu tempo não provêm apenas da reflexão dos filósofos e dos teóricos, mas também do homem comum, de pensadores secundários, jornalistas populares e romancistas de grandes tiragens, cuja análise se torna interessante precisamente devido ao seu sucesso e, portanto, ao seu caráter de representatividade de parcela da opinião pública. Além disso, ao criticar a "história pelos pináculos", Winock defende a importância da análise da expressão corriqueira dos temas políticos, como "os clichês, as ideias prontas, os preconceitos, as crenças coletivas, os mitos, as palavras de ordem, os slogans", e todo um conjunto de representações ordinárias.

Pois bem. Para Eduardo, o capital estrangeiro "não passa do soro fisiológico necessário ao bom funcionamento do nosso sistema econômico, e sem o qual, estaríamos ainda hoje no mais detestável primitivismo industrial, agrícola e cultural". (PALMÉRIO, 1949, p.44-45). É interessante notar que, quando o assunto é a cultura, Palmério era nacionalista declarado, chegando a insurgiu-se ferozmente quando um grupo de grã-finos cariocas propôs a criação do "Clube do Swing" para difundir a dança estadunidense. Ao contrário dos jovens da chamada "geração 45", por exemplo, que reagiam contra o regionalismo e o nacionalismo literário em nome da produção de uma literatura universal (GAMA, 1998, p.122), para Palmério, a sociedade deveria instalar a Sociedade Protetora 
do Samba, pois somente essa música tipicamente brasileira conseguiria expressar "todas as tendências da raça" (PALMÉRIO, 1949, p.41).

O cronista defendeu o salário-família, buscando contudo a argumentação de que os patrões deveriam deixar de ser "egoístas" e "desumanos". (Mais uma vez a questão ética e moral se sobressaindo à discussão técnico-político-econômica.) "Melhor do que fundar creches, orfanatos, abrigo de menores e outras instituições em que os meninos são criados como pintos de chocadeira elétrica, seria auxiliar os pais a criá-los em casa (PALMÉRIO, 1949, p.111)". Em outra crônica, deixou bastante clara a sua posição sobre os menores abandonados:

Já afirmamos e repetimos algumas centenas de vezes que, no Brasil, o problema dos menores é um dos maiores. Mas não será com creches e asilos que se resolverá este problema. Estes estabelecimentos só poderão prestar serviços aos órfãos. Quem deve cuidar dos filhos são os pais, nunca os estranhos. A Campanha Nacional da Criança devia cuidar dos pais, proporcionando-lhes meios de cuidar dos filhos, e não tirando-lhes para criá-los como pinto de chocadeira elétrica. (PALMÉRIO, 1949, p. 129)

Em uma crônica sobre a campanha do Serviço Social do Estado de São Paulo, que em fins dos anos 1940 pedia para que a população não concedesse esmolas aos "falsos" mendigos de rua, Palmério assumiu um tom bastante crítico. "E por que somente profligarmos a vagabundagem dos pobres, e não a dos ricos, que é a mais nefasta á sociedade?" Para ele, a esmola é sempre mais confortadora para quem dá do que para quem recebe. "O gado não defeca para adubar o solo, e sim para aliviar o intestino. Com a esmola dá-se coisa parecida (PALMÉRIO, 1949, p.82-83)". Em outra crônica, ele fez críticas contundentes contra o farisaísmo:

Mas acontece que, muitas pessoas dão pela vaidade de dar, e não pela vontade insopitável de minorar os sofrimentos alheios. Dão porque gostam de se salientar como caridosos, quando na verdade não passam de autênticos vaidosos, incapazes de passar às mãos de um mendigo uma moeda de um cruzeiro, não tendo um conhecido perto para ver (Idem).

Em outra crônica, Palmério ironizou a profunda ambiguidade da opinião dos cidadãos perante a renda dos mendigos. "Não 
sabemos por que (...) a sociedade não encara com simpatia a renda dos mendigos, muito embora o mendigo, em si, desperte os sentimentos filantrópicos de todos. Coisa singular: dá-se dinheiro aos mendigos, mas não se quer que os mendigos ganhem dinheiro. Veja lá se é possível entender-se isto! (PALMÉRIO, 1949, p.165)”. Assim, se quisermos encontrar o cerne das ideias políticas representadas nas crônicas de Eduardo Palmério, devemos buscá-la não no cardápio das ideologias programáticas, mas em um espírito ético, moral e humanista, tal como fica expresso nesse texto:

Será que tudo tem valor neste mundo: a sociedade, os costumes, o conceito, a opinião, e só as nossas convicções íntimas é que não vale nada?

Será este mundo uma grande assembléia em que só prevalecem os ditames que uma maioria impôs e que há de se perpetuar indefinidamente sem que seja ouvida, sequer, a opinião daqueles que tiveram a veleidade de duvidar da perfeição de seus constituintes?

Deve o homem sacrificar a sua própria felicidade, porque gozando-a fere a suscetibilidade de um mundo que lhe é indiferente, senão hostil?

Quem é o egoísta, nesse caso, aquele que dá cumprimento aos ditames de sua própria consciência, ou os outros, que, para não estremecer a estrutura de um edifício em ruínas, o manietam nos laços pérfidos de uma rede de intrigas e convenções?

Uma só lei, que impedisse aos homens ofender ao seu semelhante, seja humilhando-o, desprezando-o ou explorando-o, garantiria a paz e o equilíbrio universais. (PALMÉRIO, 1943a, p.4).

Por trás do humor e do sarcasmo, portanto, o que parecia inspirar a produção de Eduardo Palmério era uma profunda desilusão frente à corrupção de valores que ele enxergava em sua época. Por exemplo, na ocasião do lançamento do livro "Solteiros no Civil e no Religioso”, José Mendonça, colega jornalista que, ao contrário de Eduardo, jamais deixaria a sua Uberaba, já havia notado que, a despeito da sátira, a obra do humorista estava carregada de um "doloroso de amargura, de tristeza, de desalento".

O romance de Eduardo Palmério revela a trama de interesses ocultos que se desenrola entre homens de negócios, tubarões, jornalistas, homens de propaganda, aventureiros, meretrizes. É um retrato exato do atual ambiente de negócios, da prosperidade e do desregramento em que vivemos. A imoralidade que impera no setor-teto da vida moderna é o caldo de cultura 
em que se agitam e vivem as personagens do livro. $O$ que se passa em São Paulo, passa-se no Rio, em Nova York ou em Paris: o dinheiro redime todos os pecados (MENDONÇA, 1951, p.2).

Da mesma forma, o jornalista Ruy Novais, também da imprensa uberabense, argumentou que, naquela obra, Eduardo Palmério fizera uma caricatura mais verossímil do que pitoresca do cotidiano de um jornal paulista de grande circulação. "Os personagens agem sob o aguilhão de ambições despidas de nobreza, impulsionados pelos desejos ou interesses imediatos." (NOVAES, 1951, p.6). Sob a máscara do sarcasmo, escondia-se um cronista desiludido.

\section{Conclusões}

Em síntese, observamos que o interesse pela leitura e pela escrita; o gosto pelos ditos espirituosos; a impaciência zombeteira com a falta de inteligência; a ironia; o deboche do luxo, da pompa e das maneiras afetadas; a denúncia do farisaísmo, da bajulação e das veleidades burguesas; a consciência da teatralização social, a crítica sociopolítica; a desconfiança e o ceticismo com os partidos tradicionais; o interesse em pensar os problemas nacionais com independência intelectual; o pensamento humanista de inspiração cristã; a desilusão com a corrupção geral dos valores e um nacionalismo que parecia nascer de uma nostalgia provinciana inviabilizada pela vida cosmopolita eram características bem marcantes do ethos de Eduardo Palmério.

Como argumenta Jorge de Sá (1997), a sedução da crônica se encontra precisamente nas suas características híbridas, que transitam entre o Jornalismo e a literatura, e que privilegiam um texto curto, redigido em linguagem descompromissada, coloquial e, portanto, muito próxima do cotidiano do leitor. Produção típica da cultura de massa - por se difundir, acima de tudo, nos periódicos - a crônica também cumpre, entre as mais diversas funções, o objetivo de oferecer ao noticiário uma interpretação alternativa, que contemple as subjetividades do raciocínio do autor. Essas características fazem com que o cronista dialogue com as referências culturais dos leitores e, em última instância, passe a representar os valores, o sistema moral e as ideias políticas deste público. 
Para Berstein (RIOUX; SIRINELLI, 1998, p.349-363), a "cultura política" deve ser compreendida como uma espécie de código ou de um conjunto de referências difundidas em uma sociedade, de modo a constituir-se como um sistema mais ou menos coerente de normas e valores que, de alguma forma, condicionam a representação que essa sociedade faz de si mesma, do seu passado e do seu

futuro. É comum que essa visão de mundo se forme através de uma interpretação fundada em vulgatas, estereótipos, palavras-chave, fórmulas repetitivas, ritos, símbolos e todos aqueles elementos típicos de um texto coloquial, tal como vemos na crônica.

Nesse sentido, notamos que Eduardo Palmério representava a cultura política de uma parcela da opinião pública que, nos primeiros anos após da queda da ditadura e da abertura política, não se enquadrava nas divisões partidárias ou ideológicas apresentadas no cenário político nacional e internacional, marcado pelo início da polarização da Guerra Fria. Sua crítica satírica à corrupção e à depravação dos valores está ligada ao contexto de abertura política e de expectativas de direitos e de liberdades individuais experimentadas por toda uma geração de jornalistas após a queda de Vargas. Além disso, Palmério expressava uma cultura política que, para além dos sectarismos e superando as perspectivas da direita/esquerda (ou do capitalismo/comunismo), concebia o desenvolvimento brasileiro, acima de tudo, pela perspectiva da ética, da moral e do humanismo.

\section{Referências}

ANDRADE, Cândido Teobaldo de Souza. Mistificações de relações públicas. Portal de relações públicas e transmarketing. S/l. S/d. Disponível em: $<$ http://www.portal-rp.com.br/bibliotecavirtual/teobaldodeandrade/teobaldo01/0284.pdf>. Acesso em: 19 jul. 2011.

ARRIGUCCI JR., Davi. Enigma e comentário: ensaios sobre literatura e experiência. São Paulo, Companhia das Letras, 2001.

A LIVRARIA ABC aos seus fregueses. Lavoura e Comércio, Uberaba, 2 jun. 1941. p. 6.

BARBOSA, Marinalva. História cultural da imprensa: Brasil: 1900-2000. Rio de Janeiro: Mauad, 2007. 
FUNDAÇÃO CASA DE RUI BARBOSA. A crônica: o gênero, sua fixação e suas transformações no Brasil. Campinas; Rio de Janeiro: UNICAMP; Fundação Casa de Rui Barbosa, 1992.

COUTINHO, Afrânio. Notas de Teoria Literária. Rio de Janeiro, Civilização Brasileira, 1978

COUTINHO, Afrânio; SOUSA, José Galante. Enciclopédia de literatura brasileira, Volume 1. Global Editora, 2001.

DR. EDUARDO Palmério. Lavoura e Comércio, Uberaba, 24 maio 1941. p. 2.

DR. EDUARDO Palmério. Lavoura e Comércio, Uberaba, 18 maio 1943. p. 3.

DUARTE, Jorge; BARROS, Antonio. Métodos e técnicas de pesquisa em Comunicação. São Paulo: Atlas, 2005.

DUARTE, Paulo. História da imprensa em São Paulo. São Paulo: Escola de Comunicações e Artes, Universidade de São Paulo, 1972.

FONSECA, André Azevedo da. A consagração do mito Mário Palmério no cenário político do Triângulo Mineiro (1940-1950). 2010. 335 f. Tese (Doutorado em História) - Universidade Estadual Paulista "Julio de Mesquita Filho", 2010.

. Eduardo Palmério satirizou costumes burgueses. Observatório da Imprensa, São Paulo, 30 maio 2006. Disponível em: < http://observatoriodaimprensa.com.br/news/view/eduardo-palmerio-satirizou-costumes-burgueses $>$. Acesso em 13 jul. 2011.

GAMA, Lúcia Helena. Nos bares da vida: produção cultural e sociabilidade em São Paulo, 1940-1950. São Paulo: Senac, 1998.

LIRA NETO. Maysa: só numa multidão de amores. Rio de Janeiro: Globo Livros, 2007.

LIVRARIA A.B.C. - Uma tradição de eficiência a serviço de Uberaba. Lavoura e Comércio, Uberaba, 24 dez. 1956. p. 3.

LOROTOFF, Camarada. A grande mamata. São Paulo: s/n, 1948.

MARTINS, Ana Luiza; DE LUCA, Tânia Regina. Imprensa e cidade. São Paulo: UNESP, 2006. 
. História da imprensa no Brasil. São Paulo: Contexto, 2008.

MATOS, Santino Gomes de. Ridendo Castigat Mores. Lavoura e Comércio, Uberaba, 25 set. 1948. p 1.

MATTOS, David José Lessa. O espetáculo da cultura paulista: teatro e TV em São Paulo, 1940-1950. São Paulo: Conex, 2002

MEDICI, Ademir. O centenário do jornalista Eduardo Palmério. Setecidades. Diário do Grande ABC. Santo André. 12 jan. 2006. p. 2.

MENDONÇA, José. A grande mamata. Lavoura e Comércio, Uberaba, 21 set. 1948. p 2.

MENDONÇA, José. "Solteiros no civil e no religioso". Lavoura e Comércio, Uberaba, 11 dez. 1951. p. 2.

MENDONÇA, José. "A noite é nossa". Lavoura e Comércio, Uberaba, 29 abr. 1958. p. 2.

MINAS, João de. O dr. Francisco Faleiros, eminente líder Ademarista, me ofereceu o último besteseler de Eduardo Palmério. Lavoura e Comércio, Uberaba, 9 jan. 1952. p. 2.

NICOLAU, Jairo Marconi. História do voto no Brasil. 2. ed. Rio de Janeiro: Jorge Zahar, 2004. p. 34.

NOBRE, Freitas. História da imprensa de São Paulo. Edições LEIA, 1950.

NOVAES, Ruy de Souza. Eduardo Palmério publica o seu terceiro livro. Lavoura e Comércio, Uberaba, 14 dez. 1951. p. 6.

PALMÉRIO, Eduardo. Balões de ensaio. Lavoura e Comércio, Uberaba, 4 ago. 1943a. p. 4.

. Honra ao mérito. Lavoura e Comércio, Uberaba, 12 ago. 1943b.

Balões de ensaio. p. 6.

100 Comentários: Separados do B.O.D.E.: Boletim Oficial do Estado. Rio de Janeiro: José Olympio, 1949.

nais, 1951.

. Solteiros no civil e no religioso. São Paulo: Revista dos Tribu-

Intercom - RBCC

São Paulo, v.35, n.2, p. 6I-84, jul./dez. 2012 
. A noite é nossa. São Paulo: Distribuidora paulista de jornais e revistas livros impressos Ltda., [1958].

PALMÉRIO, Mário. Vila dos Confins. Rio de Janeiro: José Olympio, 1956.

PIMENTEL, Luís. Entre sem bater!: o humor na imprensa: do Barão de Itararé ao Pasquim 21. Singular Digital, 2004.

REMOND, René (org.). Por uma história política. 2 ed. Rio de Janeiro: FGV, 2003.

REZENDE, Eliane Mendonça Marquez de. Uberaba: uma trajetória socioeconômica (1811-1910). 1983. 99 f. Dissertação (Mestrado em História) Universidade Federal de Goiás, Goiânia, 1983.

RIOUX Jean-Pierre; SIRINELLI; Jean-François (dir.). Para uma História Cultural. Lisboa: Editorial Estampa, 1998.

RUI, Jota. A alegre história do humor no Brasil. Expressão e Cultura, 1979.

SÁ, Jorge de. A crônica. São Paulo: Autêntica, 1997.

SKIDMORE, Thomas. Brasil: de Getúlio Vargas a Castelo Branco (19341964). 6.ed. São Paulo: Paz e Terra, 1979.

SODRÉ, Nelson Werneck. História da imprensa no Brasil. 4 ed. Rio de Janeiro: Mauad, 1998.

TOTI, Gabriel. A imprensa de Uberaba. Lavoura e Comércio, Uberaba, 6 jul. 1949 .

VILAS BOAS, Sérgio. Perfis e como escrevê-los. São Paulo: Summus, 2003.

Recebido: 30.11 .2011

Aceito: 30.04 .2012 